\title{
Strategies to Improve Regeneration of the Soft Palate Muscles After Cleft Palate Repair
}

\author{
Paola L. Carvajal Monroy, D.D.S., M.Sc., Sander Grefte, Ph.D., ${ }^{\star}$ \\ Anne Marie Kuijpers-Jagtman, D.D.S., Ph.D., Frank A.D.T.G. Wagener, Ph.D., \\ and Johannes W. Von den Hoff, Ph.D.
}

Children with a cleft in the soft palate have difficulties with speech, swallowing, and sucking. These patients are unable to separate the nasal from the oral cavity leading to air loss during speech. Although surgical repair ameliorates soft palate function by joining the clefted muscles of the soft palate, optimal function is often not achieved. The regeneration of muscles in the soft palate after surgery is hampered because of (1) their low intrinsic regenerative capacity, (2) the muscle properties related to clefting, and (3) the development of fibrosis. Adjuvant strategies based on tissue engineering may improve the outcome after surgery by approaching these specific issues. Therefore, this review will discuss myogenesis in the noncleft and cleft palate, the characteristics of soft palate muscles, and the process of muscle regeneration. Finally, novel therapeutic strategies based on tissue engineering to improve soft palate function after surgical repair are presented.

\section{Introduction}

C LEFT LIP AND/or palate (CLP) is the most common congenital facial malformation in humans. It occurs in about $1 / 500$ to $1 / 1000$ births, with ethnic and geographic variation. ${ }^{1}$ This disorder is generally divided into two groups: clefts involving the lip with or without cleft palate and isolated cleft palate ${ }^{2}$ (Fig. 1). CLP can also be part of a syndrome when it is associated with other congenital defects. ${ }^{3}$ In this review we will focus on clefts involving the soft palate.

Children with a cleft in the soft palate have difficulties with speech, swallowing, and sucking. These patients are unable to separate the nasal from the oral cavity; a phenomenon known as velopharyngeal dysfunction. Surgical repair is required to close the defect and to reconstruct the muscle sling of the $\mathrm{m}$. levator veli palatini (LVP), the major muscle of the soft palate ${ }^{4}$ (Fig. 2). It ensures optimal function and normal speech development. ${ }^{5,6}$ However, about $10 \%$ to $30 \%$ of the treated patients remain unable to achieve adequate velopharyngeal function. ${ }^{7,8}$ This results in hypernasal speech that often requires additional surgical corrections. Diverse factors are attributed to suboptimal repair such as age at the time of the surgery, skills and experience of the surgeon, type and extension of the cleft, fibrosis, damage of the motor and proprioceptive innervation, and abnormal fiber type distribution. ${ }^{7,9-12}$

This review will highlight the myogenesis and characteristics of the soft palate muscles in the noncleft and cleft palate, and the process of muscle regeneration. We postulate that muscle healing and function after soft palate repair can be improved by adjuvant strategies from the field of regenerative medicine. How these novel adjuvant strategies based on tissue engineering could improve muscle healing and prevent velopharyngeal dysfunction after surgical repair will be discussed.

\section{Soft Palate Myogenesis}

The muscles of the soft palate and those controlling jaw movement, facial expression, and pharyngeal (throat) and laryngeal (voice box) function are known as branchiomeric muscles. ${ }^{13,14}$ The formation of the soft palate muscles starts already early in embryonic development and yields five pairs of muscles: (1) the tensor veli palatini (TVP), (2) the LVP, (3) the palatopharyngeus (PP), (4) the palatoglossus (PG), and 5) the uvulae (U) (Fig. 2). Mesenchymal condensations of the individual soft palate muscles emerge sequentially, starting from the sixth week of gestation in humans, with the TVP appearing first and the U last. Their

All work was performed in the Department of Orthodontics and Craniofacial Biology, at the Nijmegen Centre for Molecular Life Sciences of the Radboud University Nijmegen Medical Centre.

Department of Orthodontics and Craniofacial Biology, Nijmegen Centre for Molecular Life Sciences, Radboud University Nijmegen Medical Centre, Nijmegen, The Netherlands.

*Current affiliation: Department of Biochemistry, Nijmegen Centre for Molecular Life Sciences, Radboud University Nijmegen Medical Centre, Nijmegen, The Netherlands. 

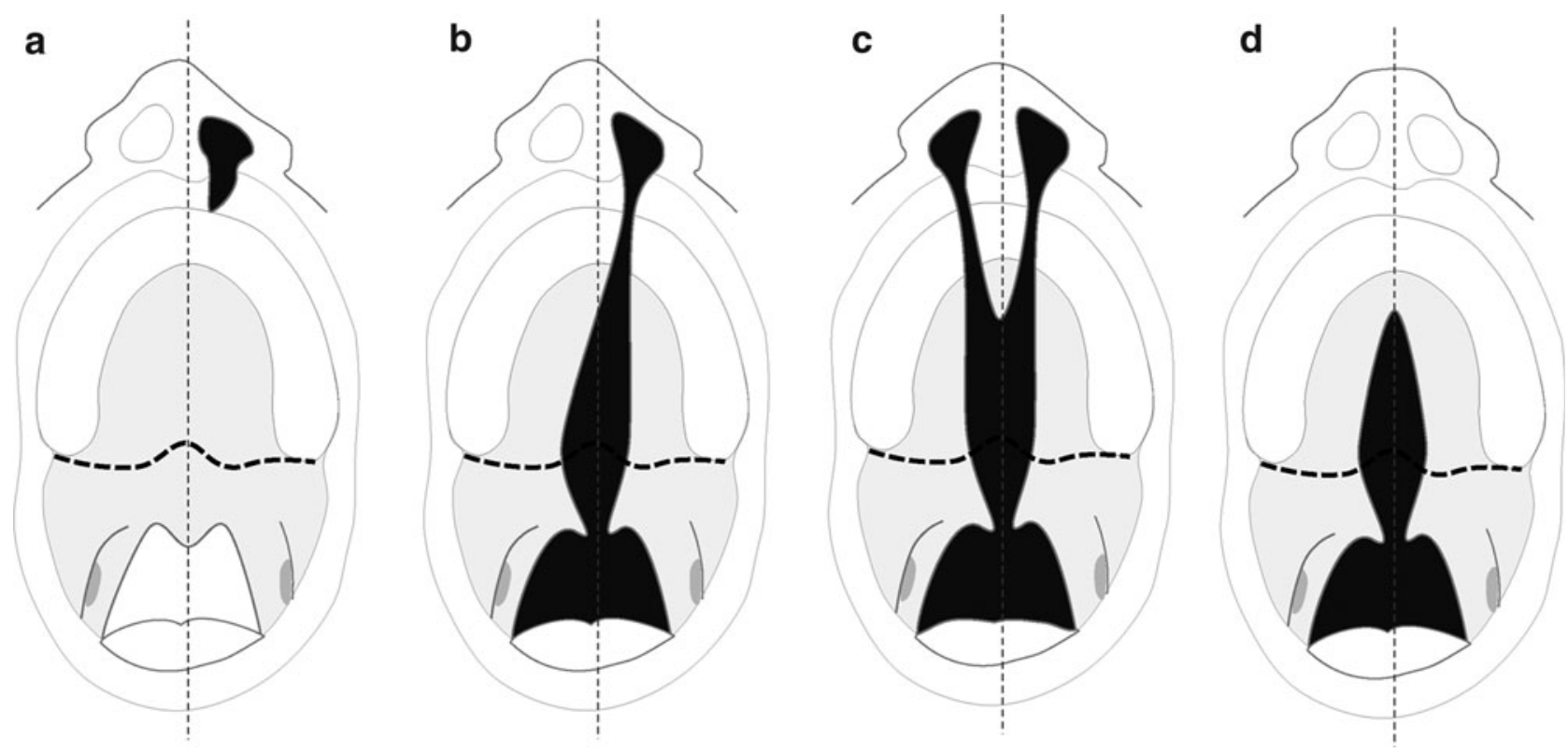

FIG. 1. Cleft lip and/or palate. (a) Cleft lip. (b) Unilateral cleft lip and palate. (c) Bilateral cleft lip and palate. (d) Isolated cleft palate. The dashed line indicates the posterior border of the hard palate.

full morphological development is completed after the 17 th week of intrauterine life. The hard palate is already fused at this stage. The masticatory muscles and the TVP develop at the same time, and are followed by the morphogenesis of the LVP, PP, PG, and U muscles, and by the palatal aponeurosis
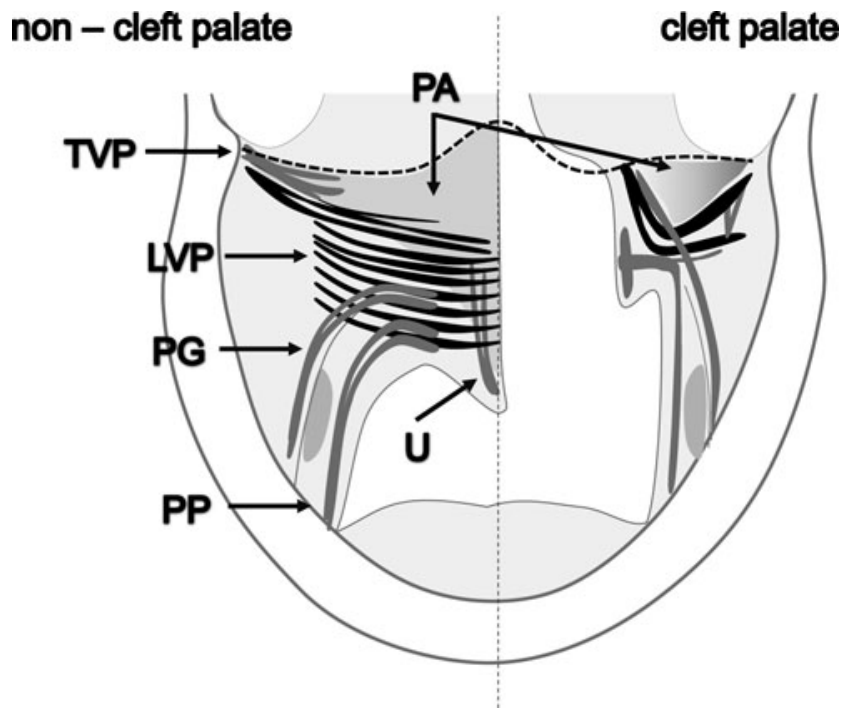

FIG. 2. Muscles of the soft palate. m. tensor veli palatini (TVP), m. levator veli palatini (LVP), the major muscle of the soft palate (black), m. palatopharyngeus (PP), m. palatoglossus (PG), m. uvulae (U), and palatal aponeurosis (PA). The dashed line indicates the posterior border of the hard palate. Notice the abnormal insertion of the soft palate muscles into the posterior border of the hard palate at the cleft side. In this area disorganized myofibers are present. Cleft palate muscles are limited to isometric contractions and often underdeveloped.
(PA). ${ }^{15,16}$ The development of the soft palate muscles in cleft patients is delayed compared with noncleft individuals. ${ }^{17}$

\section{Soft Palate Muscles in the Normal and Cleft Palate}

The soft palate is formed by an interweaving of muscles from the skull base (TVP and LVP), tongue (PG), and pharynx (PP; Fig. 2). All muscles extend from nearby bony structures and are inserted into the PA located in the center of the soft palate (Fig. 2). Hence, all muscles have only one skeletal insertion, with the exception of the $U$, which is a completely intrinsic muscle of the soft palate without bony attachment. In the cleft palate, the muscles are attached to the posterior border of the hard palate (Fig. 2). The abnormal insertions of the muscles, in particular the LVP, in cleft palate patients prevent normal functioning. These muscles have two instead of one skeletal attachments limiting them to isometric contractions. ${ }^{18}$ As a result, the cleft muscles pull the two halves of the soft palate in a superior and lateral direction, causing further widening of the cleft. ${ }^{19}$ In addition, the LVP may become severely atrophic because of reduced function, and often has only half of the thickness found in healthy newborns. The LVP myofibers are also disorganized next to the cleft margin. ${ }^{16,17}$

Both slow and fast fibers are present in the soft palate muscles. Slow fibers are highly resistant to fatigue, with a low activation threshold, whereas fast fibers are more fatiguable, with a higher activation threshold. In noncleft individuals, the LVP contains predominantly slow fibers, ${ }^{20,21}$ whereas in cleft individuals it contains a higher proportion of fast fibers and a reduced capillary supply compared with normal LVP muscles. ${ }^{22-24} \mathrm{~A}$ fetal myosin heavy chain isoform is also present in a small number of fibers in all palatal muscles. In comparison with limb muscles, the individual and intramuscular variability in fiber diameter of the LVP is much larger. ${ }^{21}$ The higher number of fast fibers in cleft patients may cause the increased fatigability of the LVP during speech, ${ }^{23}$ which 
contributes to velopharyngeal dysfunction. ${ }^{25}$ Further, fast fibers are more prone to contraction-induced injury. ${ }^{24,26,27}$

\section{Muscle Regeneration in the Soft Palate}

In general, muscles possess a strong ability to regenerate after injury. Satellite cells (SatCs) ${ }^{28}$ are the primary muscle stem cells, and are responsible for postnatal muscle growth, maintenance, and repair. After injury, adjacent SatCs become activated and migrate to the site of injury, proliferate, differentiate, and fuse to form new myofibers or repair damaged ones. ${ }^{29,30}$ In addition, signaling molecules from infiltrating macrophages, injured myofibers, and the disrupted extracellular matrix participate in the regeneration process. ${ }^{29-31}$ The formation of scar tissue may prevent proper muscle regeneration. ${ }^{32-34}$ The majority of studies on muscle regeneration have been performed in limb muscles, while studies on head muscles are scarce. Muscles from the limbs and the head differ in several aspects. Skeletal muscles from the trunk and limbs are derived from the somites ${ }^{35}$ during embryonic development, while most head muscles including those of the soft palate are derived from the branchial arches. ${ }^{36-38}$ The masseter muscle, a branchiomeric muscle, seems to contain less SatCs than limb muscle. ${ }^{39}$ Freeze or crush injuries in the masseter muscle also regenerate much slower than similar injuries in limb muscles. ${ }^{40}$ Moreover, much more fibrous connective tissue is formed in the damaged area. Proliferating SatCs from limb and head muscle also express a distinct profile of transcription factors. ${ }^{39}$ In vitro, SatC-derived myoblasts from masseter proliferate more but differentiate later than those from limb muscle. Remarkably, both SatC populations are similarly able to regenerate limb muscle injuries after transplantation. ${ }^{39}$ These observations support the crucial role of the SatC niche in muscle regeneration.

As mentioned, fast fibers are predominantly found in cleft palate muscles compared with normal soft palate muscles. ${ }^{22-24}$ In general, the percentage of SatCs in fast muscle fibers is significantly lower than in slow muscle fibers. ${ }^{41,42}$ This may further decrease the SatC number in cleft palate muscles. In addition, in vitro studies show that SatCs from fast muscle fibers proliferate less than those from slow muscle fibers. ${ }^{39}$ In rodent models for muscle atrophy induced by disuse, SatCs decrease in number and display reduced function. ${ }^{43-45}$ Further, impaired macrophage recruitment to the site of injury and impaired macrophage function has been recently demonstrated in this muscle atrophy model. ${ }^{46}$ A similar situation may exist in cleft palate muscles that are limited to isometric contractions and are therefore also atrophied. The accompanying poor capillary supply may further impair the regeneration process and promote fibrosis. ${ }^{18,19}$

Disorganized muscle fibers are found at the attachment of cleft palate muscles to the posterior border of the palatal bone. ${ }^{16,17}$ This possibly prevents further postnatal myofiber maturation by normal function. ${ }^{47}$

In summary, the lower regenerative capacity of branchiomeric muscles in general, and the specific properties of cleft palate muscles may compromise muscle regeneration following surgical repair in cleft patients.

\section{Soft Palate Muscles in Animal Models}

Several mammalian species have been used for the study of the normal and clefted palate. The most frequently used animal models are goats, mice, and rats. ${ }^{48-53} \mathrm{Up}$ to now, tissue engineering studies in the soft palate have not been performed. Therefore, the selection of an appropriate animal model for the study of the regeneration of the soft palate muscles is highly important. The use of an existing congenital cleft palate model in the goat ${ }^{51,54-56}$ is not feasible due to the high costs that limits group size. Cleft palate models in knockout mice are generally limited to embryological studies due to high mortality after birth, and lack of reproducibility of the induced clefts. ${ }^{57-60}$ However, the widespread use of rodents for fundamental and preclinical research ensures the availability of extensive tools and markers. In addition, their low cost and ease of handling make them the most suitable model for the development of soft palate muscle engineering techniques.

Similar to humans, the soft palate muscles in rodents possess a mixture of slow and fast fibers, ${ }^{61}$ and play an important role in swallowing and respiration. ${ }^{61,62}$ In addition, the soft palate muscles in cleft animals also run parallel to the margins of the cleft, and disorganized myofibers are present. ${ }^{60}$ In contrast to humans, ${ }^{17}$ the development of the palatal muscles in cleft palate mice is not delayed. ${ }^{63}$

The advantage of the rat over the mouse is its larger body size favoring surgical manipulation of the soft palate. This makes the rat the most suitable animal for experimental research on muscle regeneration of the soft palate.

\section{Tissue Engineering to Improve the Outcome of Surgery}

As mentioned in the previous sections, several biological factors have been attributed to functional impairment of the soft palate after surgical correction (Fig. 3): (1) Low intrinsic regenerative capacity of soft palate muscles. As shown, branchiomeric muscles including those of the soft palate, have a low number of SatCs with a low rate of differentiation compared with limb muscles, which may contribute to their poor regenerative capacity. (2) Muscle properties related to clefting. Clefted soft palate muscles contain a lower number of myofibers and are highly disorganized close to the cleft margin. This impedes the function of the reconstructed muscle. (3) The development of fibrosis. The main harmful effect of surgery is the development of muscle fibrosis, which impairs the regeneration of muscle fibers. Strategies based on tissue engineering may ameliorate the functional outcome of surgical repair by approaching these three main issues.

Another factor that may influence the regeneration of palatal muscles is age. In general, the number of SatCs in growing postnatal muscle is about $30 \%-35 \%$ of all nuclei. ${ }^{64-66}$ In adulthood, only $1-4 \%$ of all nuclei belong to the SatC population. ${ }^{67}$ Surgical repair of the soft palate generally takes place in early childhood (6-36 months of age). After birth, the soft palate muscles are still immature. A large number of SatCs are present to fulfil the demands of growth. ${ }^{68}$ In contrast, newborn SatCs seem to engraft less efficiently than their adult counterparts. ${ }^{69}$ This should be taken into account when developing tissue engineering strategies for soft palate muscles.

\section{Improving the intrinsic regenerative properties of the soft palate muscles}

Isolated SatCs may be used for cell-based therapy to improve the regenerative capacity of the soft palate muscles. It has 
Before surgery
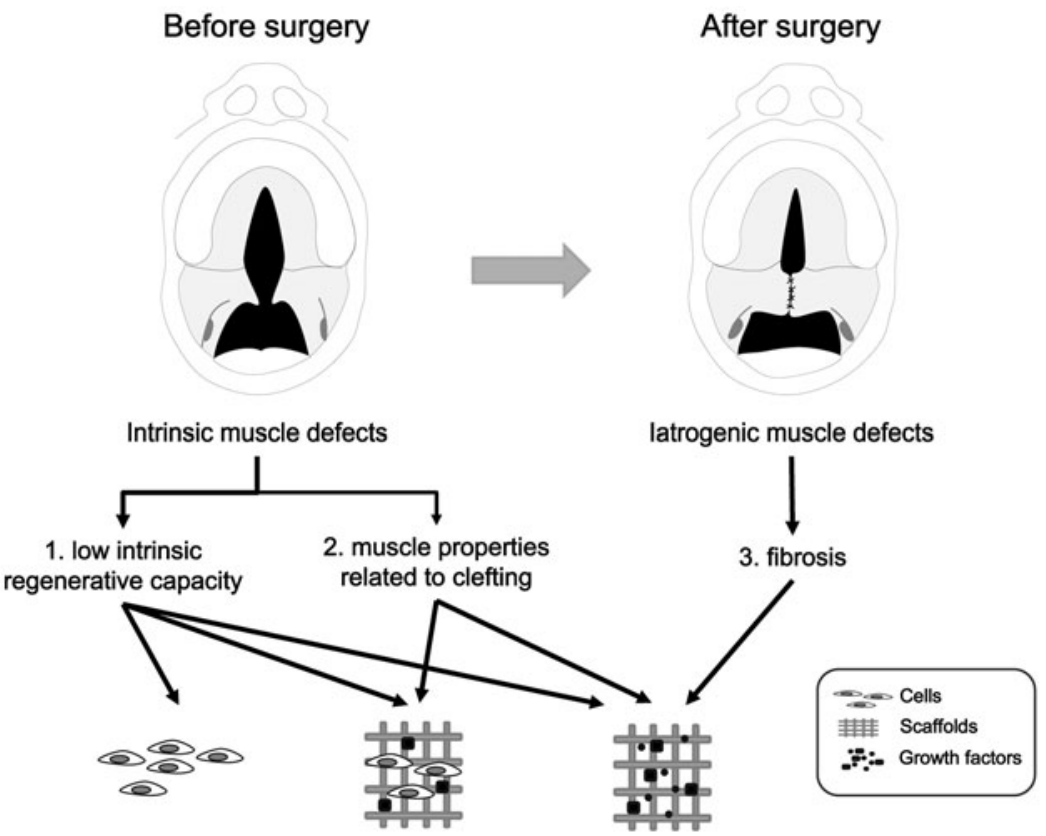

FIG. 3. Muscle problems related to clefting. Before surgery: (1) Low intrinsic regenerative capacity: less number of satellite cells with a low rate of differentiation, (2) Muscle properties related to clefting: clefted soft palate muscles contain lesser number of myofibers and are highly disorganized. After surgery: (3) Fibrosis. Adjuvant strategies based on tissue engineering using (stem) cells, growth factors, and scaffolds may improve the outcome after surgery. been demonstrated that transplanted SatCs are able to form new myofibers and to self-renew. ${ }^{70}$ This approach has already been used for the treatment of a variety of diseases such as muscular dystrophy ${ }^{71}$ and myocardial infarction. ${ }^{72-74}$ Unfortunately, the success of transplantation of SatCs and myoblasts has only been limited. After isolation, SatCs seem to lose their regenerative capacity in culture. In addition, their survival and migration to the site of injury after injection is limited. ${ }^{75,76}$

Mesenchymal and embryonic stem cells can also differentiate into skeletal muscle. ${ }^{77-79}$ However, only a small fraction of cultured mesenchymal stem cells undergo fusion into myofibers ${ }^{80}$ suggesting that these cells may not be an appropriate cell type for therapeutic use. ${ }^{81}$ Embryonic stem cells have a large potential for cell-based therapies for a wide range of diseases. ${ }^{82,83}$ These cells may offer additional advantages such as their larger replicative potential, and the possibility to perform gene targeting. ${ }^{84}$ However, embryonic stem cell-derived myogenic populations with possible therapeutic value have not been found up to now.

Alternatively, other nonmuscle stem cells such as mesoangioblasts and pericytes also have myogenic potential. ${ }^{85,86}$ Both mesoangioblasts and pericytes can be delivered systemically because of their ability to cross the endothelium. This approach was successful for cell therapy in muscular dystrophy. ${ }^{86,87}$ Nevertheless, the exact ability of nonmuscle stem cells for muscle regeneration and their possible use in cell therapy remain to be elucidated. ${ }^{8-91}$

As an alternative approach, the recruitment, proliferation, and differentiation of SatCs already present in the soft palate muscle may be stimulated by specific growth factors. As mentioned, muscle growth and regeneration is controlled by locally-produced growth factors, which stimulate SatCs such as insulin-like growth factor 1 (IGF-1) and fibroblast growth factor 2 (FGF-2). IGF-1 favors muscle regeneration by increasing the rate of SatC proliferation and the formation of myotubes. $^{92-96}$ Similarly, FGF-2 stimulates muscle regeneration in vitro and in vivo by promoting the proliferation of myoblasts after injury. ${ }^{97-100}$ Moreover, it facilitates the re- cruitment and proliferation of SatCs ${ }^{101}$ and promotes angiogenesis. ${ }^{102,103}$ However, when growth factors are injected in vivo, they rapidly lose their biological activity due to diffusion and/or enzymatic inactivation. ${ }^{104}$ Because of this, growth factors and attachment motifs have been incorporated into biodegradable scaffolds for controlled release. ${ }^{105}$ With microspheres prepared from materials such as polylactic-co-glycolic acid, the release of such factors can be controlled. ${ }^{106-108}$ In addition, fibrin and gelatin hydrogels can give a sustained release of (growth) factors. ${ }^{109-112}$ These new techniques may improve the delivery of factors to the site of injury and stimulate muscle regeneration.

Although cell-based therapy seems to be promising for the treatment of genetic muscle defects, it is probably not a feasible option for cleft palate because it is a completely different type of condition. For example, in degenerative diseases like Duchenne muscular dystrophy, multiple cycles of muscle degeneration and regeneration deplete the SatC population. ${ }^{113}$ In contrast, in cleft palate, muscle SatCs are preserved. In summary, growth factors and cytokines in a suitable delivery system may stimulate proliferation and differentiation of resident SatCs in the soft palate muscles after surgical repair.

\section{Correcting cleft-associated muscle abnormalities}

Muscle is a highly organized structure consisting of long, parallel multinucleated myotubes to generate sufficient force for contraction. ${ }^{114}$ Therefore, the random myofiber orientation in cleft palate muscles impedes normal function after surgical repair. The reduced function limits the switch from a fast to a slow myofiber type. ${ }^{12,24}$ This may explain the increased muscle fatigability observed in patients with velopharyngeal dysfunction. ${ }^{23}$

Proper alignment of regenerating myotubes may be achieved with scaffolds of specific design and surface topography. ${ }^{115}$ Myoblasts are known to respond to the surrounding topography, ${ }^{116}$ which leads to directional cell 
growth. ${ }^{115}$ Hence, different techniques have been described to control cellular alignment on micro- and nanostructured surfaces produced either by chemical or topographic patterning. These include electrospinning, ${ }^{117}$ photolithography, ${ }^{118}$ and electron beam lithography. ${ }^{19}$

Aligned nanofiber meshes can be fabricated from biocompatible polymers such as poly-lactide or poly-glycolideco lactide via electrospinning. ${ }^{119}$ Muscle cells cultured in these meshes show alignment and migration and a contractile phenotype. ${ }^{120,121}$ However, up to now the possibilities to control the mechanical properties of these polymer meshes is limited. ${ }^{120}$ In addition, slowly degrading polymers persist in the regenerated tissue for a long time. Since the repair of the soft palate is generally performed in children, later growth of the soft palate must be accommodated. Therefore, the use of rapidly degrading polymers seems to be more suitable. Recently, it was reported that growth factors can be printed onto sub-micron polystyrene fibers. ${ }^{122,123}$ A combination of a suitable scaffold with growth factors and cytokines (e.g., stromal cellderived factor-1 $\alpha$ ) might favor migration, ${ }^{124}$ differentiation of resident SatCs, and induce myofiber alignment.

Particularly in patients with wider clefts, the amount of soft palate tissue is limited, which causes tension at the junction of the hard and soft palate after surgical repair. It has been proposed that scarring affects the length of the soft palate in anteroposterior direction, ${ }^{125}$ which depends on the specific technique used for closure. ${ }^{126}$ Alternatively, scarring may contribute to a narrowing of the residual cleft after twostage palatoplasty. ${ }^{126-128}$ The site most likely to fistulize is at the junction of the hard and soft palate. ${ }^{129}$ Fistulae usually have been associated with the type of cleft, technique and timing of repair, and the experience of the surgeon. ${ }^{130}$ Substitutes as decellularized dermal allograft have been successfully used to close wide defects while preventing fistulae formation. ${ }^{131}$ The use of scaffolds in the soft palate muscles allows a defined architecture to guide cell growth and development.

\section{Preventing secondary effects of surgery: fibrosis}

The deposition of excess ECM during regeneration may lead to fibrosis and impaired muscle function. A key factor in fibrosis is transforming growth factor-beta 1 (TGF- $\beta 1$ ). ${ }^{132,133}$ It stimulates the synthesis of collagen and other extracellular matrix components and promotes myofibroblast formation. ${ }^{134}$ Myostatin, another member of the TGF- $\beta$ family, inhibits muscle regeneration by the inhibition of SatC and myoblast proliferation. ${ }^{135-138}$ In this way, TGF- $\beta 1$ and myostatin synergistically amplify the fibrotic process after injury. In contrast, myostatin knockout mice develop less fibrosis and display improved skeletal muscle regeneration compared with wild-type mice. ${ }^{139}$

The inhibition of TGF- $\beta 1$ and myostatin may prevent fibrous scar formation and improve muscle healing after injury. ${ }^{139}$ Decorin is a member of the small leucine-rich proteoglycan family, and it reduces both TGF- $\beta 1$ and myostatin activity. ${ }^{139-142}$ It thereby enhances the proliferation and differentiation of myogenic cells, ${ }^{143}$ and prevents fibrosis. ${ }^{144}$ In addition, decorin upregulates the expression of a variety of myogenic markers including Myf5, Myf6, MyoD, and myogenin in vitro. ${ }^{145}$ Hepatocyte growth factor increases decorin production by fibroblasts. ${ }^{146}$ Furthermore, small signaling molecules such as nitric oxide down regulate TGF$\beta 1$ activity. ${ }^{147}$ However, the importance of nitric oxide in muscle regeneration must be further elucidated. In summary, the use of decorin and other factors that inhibit TGF- $\beta 1$ and myostatin may prevent scar formation after surgical correction of the soft cleft palate. A disadvantage might be that anti-fibrotic therapy can diminish narrowing of the residual cleft after two-stage palatoplasty. Therefore, the longterm effects of novel therapies based on tissue engineering in such a complex anatomical environment is hard to predict. Further research should elucidate the final outcome of these new therapeutic approaches.

\section{Conclusions}

This review discusses the development and characteristics of the soft palate muscles in the noncleft and cleft palate and the process of muscle regeneration. Finally, tissue engineering strategies are proposed to improve muscle regeneration after the closure of the soft palate. The regeneration of muscles in the soft palate after surgery is hampered because of (1) their low intrinsic regenerative capacity, (2) muscle properties related to clefting, and (3) the development of fibrosis. We propose the following strategies based on tissue engineering, to improve the functional outcome after surgical repair.

To improve muscle regeneration (problem 1), growth factors and cytokines might be applied to the surgical wounds by incorporation into scaffolds or microspheres. The growth factors should enhance SatC recruitment from the adjacent muscle tissue and their proliferation and differentiation into new myofibers. This will enhance the intrinsic regeneration capacity of the soft palate muscles, and thereby increase the functional outcome of surgery in terms of number and maturation of myofibers.

Suitable scaffolds may also support the alignment of myofibers and compensate the limited amount of tissue in clefted muscles (problem 2). These scaffolds should offer an architecture that guides cell growth and myofiber formation. In terms of function, this approach will increase muscle volume and force generation by the soft palate muscles.

To prevent fibrosis (problem 3), TGF- $\beta 1$ and myostatin activity can be inhibited by factors such as decorin. This will reduce the formation of fibrotic tissue and stimulate proliferation of myoblasts. The function of the soft palate muscles after repair will thus improve by allowing myofiber formation and alignment (approaches 1 and 2).

Wrapping up, scaffolds that give a controlled release of growth factors, guide the alignment of new myofibers, and prevent fibrosis might improve muscle regeneration after surgical repair of the cleft soft palate. Nevertheless, further research is required in order to develop these functionalized scaffolds.

\section{Disclosure Statement}

No competing financial interests exist.

\section{References}

1. Gritli-Linde, A. Molecular control of secondary palate development. Dev Biol 301, 309, 2007.

2. Mossey, P.A., Little, J., Munger, R.G., Dixon, M.J., and Shaw, W.C. Cleft lip and palate. Lancet 374, 1773, 2009. 
3. Calzolari, E., Pierini, A., Astolfi, G., Bianchi, F., Neville, A.J., and Rivieri, F. Associated anomalies in multimalformed infants with cleft lip and palate: an epidemiologic study of nearly 6 million births in 23 EUROCAT registries. Am J Med Genet A 143, 528, 2007.

4. Boorman, J.G., and Sommerlad, B.C. Levator palati and palatal dimples: their anatomy, relationship and clinical significance. Br J Plast Surg 38, 326, 1985.

5. Bae, Y.C., Kim, J.H., Lee, J., Hwang, S.M., and Kim, S.S. Comparative study of the extent of palatal lengthening by different methods. Ann Plast Surg 48, 359, 2002.

6. Braithwaite, F., and Maurice, D.G. The importance of the levator palati muscle in cleft palate closure. Br J Plast Surg 21, 60, 1968.

7. Marrinan, E.M., LaBrie, R.A., and Mulliken, J.B. Velopharyngeal function in nonsyndromic cleft palate: relevance of surgical technique, age at repair, and cleft type. Cleft Palate Craniofac J 35, 95, 1998.

8. Morris, H.L. Velopharyngeal competence and primary cleft palate surgery, 1960-1971: a critical review. Cleft Palate J 10, 62, 1973.

9. Yamaoka, M., Furusawa, K., and Kumai, T. Muscle spindle distribution in the levator veli palatini muscle in the rat. Cleft Palate Craniofac J 29, 271, 1992.

10. Rintala, A.E., and Haapanen, M.L. The correlation between training and skill of the surgeon and reoperation rate for persistent cleft palate speech. Br J Oral Maxillofac Surg 33, 295, 1995.

11. Persson, C., Elander, A., Lohmander-Agerskov, A., and Soderpalm, E. Speech outcomes in isolated cleft palate: impact of cleft extent and additional malformations. Cleft Palate Craniofac J 39, 397, 2002.

12. Hanes, M.C., Weinzweig, J., Panter, K.E., McClellan, W.T., Caterson, S.A., Buchman, S.R., Faulkner, J.A., Yu, D., Cederna, P.S., and Larkin, L.M. The effect of cleft palate repair on contractile properties of single permeabilized muscle fibers from congenitally cleft goat palates. Ann Plast Surg 60, 188, 2008.

13. Harel, I., Nathan, E., Tirosh-Finkel, L., Zigdon, H., Guimaraes-Camboa, N., Evans, S.M., and Tzahor, E. Distinct origins and genetic programs of head muscle satellite cells. Dev Cell 16, 822, 2009.

14. Sambasivan, R., Gayraud-Morel, B., Dumas, G., Cimper, C., Paisant, S., Kelly, R.G., and Tajbakhsh, S. Distinct regulatory cascades govern extraocular and pharyngeal arch muscle progenitor cell fates. Dev Cell 16, 810, 2009.

15. Domenech-Ratto, G. Development and peripheral innervation of the palatal muscles. Acta Anat (Basel) 97, 4, 1977.

16. Cohen, S.R., Chen, L., Trotman, C.A., and Burdi, A.R. Softpalate myogenesis: a developmental field paradigm. Cleft Palate Craniofac J 30, 441, 1993.

17. Cohen, S.R., Chen, L.L., Burdi, A.R., and Trotman, C.A. Patterns of abnormal myogenesis in human cleft palates. Cleft Palate Craniofac J 31, 345, 1994.

18. Koch, K.H., Grzonka, M.A., and Koch, J. The pathology of the velopharyngeal musculature in cleft palates. Ann Anat 181, 123, 1999.

19. Fara, M., and Dvorak, J. Abnormal anatomy of the muscles of palatopharyngeal closure in cleft palates: anatomical and surgical considerations based on the autopsies of 18 unoperated cleft palates. Plast Reconstr Surg 46, 488, 1970.

20. Moon, J.B., Thompson, S.A., Jaeckel, E., and Canady, J.W. Muscle fiber type distribution in the normal human levator veli palatini muscle. Cleft Palate Craniofac J 35, 419, 1998.
21. Stål, P.S., and Lindman, R. Characterisation of human soft palate muscles with respect to fibre types, myosins and capillary supply. J Anat 197 (Pt 2), 275, 2000.

22. Lindman, R., Paulin, G., and Stal, P.S. Morphological characterization of the levator veli palatini muscle in children born with cleft palates. Cleft Palate Craniofac J 38, 438, 2001.

23. Hanes, M.C., Weinzweig, J., Kuzon, W.M., Panter, K.E., Buchman, S.R., Faulkner, J.A., Yu, D., Cederna, P.S., and Larkin, L.M. Contractile properties of single permeabilized muscle fibers from congenital cleft palates and normal palates of Spanish goats. Plast Reconstr Surg 119, 1685, 2007.

24. Rader, E.P., Cederna, P.S., Weinzweig, J., Panter, K.E., Yu, D., Buchman, S.R., Larkin, L.M., and Faulkner, J.A. Contraction-induced injury to single permeabilized muscle fibers from normal and congenitally-clefted goat palates. Cleft Palate Craniofac J 44, 216, 2007.

25. Tachimura, T., Nohara, K., Satoh, K., and Wada, T. Evaluation of fatigability of the levator veli palatini muscle during continuous blowing using power spectra analysis. Cleft Palate Craniofac J 41, 320, 2004

26. Macpherson, P.C., Dennis, R.G., and Faulkner, J.A. Sarcomere dynamics and contraction-induced injury to maximally activated single muscle fibres from soleus muscles of rats. J Physiol 500 (Pt 2), 523, 1997.

27. Rader, E.P., Cederna, P.S., McClellan, W.T., Caterson, S.A., Panter, K.E., Yu, D., Buchman, S.R., Larkin, L.M., Faulkner, J.A., and Weinzweig, J. Effect of cleft palate repair on the susceptibility to contraction-induced injury of single permeabilized muscle fibers from congenitally-clefted goat palates. Cleft Palate Craniofac J 45, 113, 2008.

28. Mauro, A. Satellite cell of skeletal muscle fibers. J Biophys Biochem Cytol 9, 493, 1961.

29. Ten Broek, R.W., Grefte, S., and Von den Hoff, J.W. Regulatory factors and cell populations involved in skeletal muscle regeneration. J Cell Physiol 224, 7, 2010.

30. Ciciliot, S., and Schiaffino, S. Regeneration of mammalian skeletal muscle. Basic mechanisms and clinical implications. Curr Pharm Des 16, 906, 2010.

31. Grefte, S., Kuijpers-Jagtman, A.M., Torensma, R., and Von den Hoff, J.W. Skeletal muscle development and regeneration. Stem Cells Dev 16, 857, 2007.

32. Kaariainen, M., Jarvinen, T., Jarvinen, M., Rantanen, J., and Kalimo, H. Relation between myofibers and connective tissue during muscle injury repair. Scand J Med Sci Sports 10, 332, 2000.

33. Grounds, M.D., Sorokin, L., and White, J. Strength at the extracellular matrix-muscle interface. Scand J Med Sci Sports 15, 381, 2005.

34. Cornelison, D.D. Context matters: in vivo and in vitro influences on muscle satellite cell activity. J Cell Biochem 105, 663, 2008.

35. Christ, B., and Ordahl, C.P. Early stages of chick somite development. Anat Embryol (Berl) 191, 381, 1995.

36. Kelly, R.G. Core issues in craniofacial myogenesis. Exp Cell Res 316, 3034, 2010.

37. Noden, D.M., and Francis-West, P. The differentiation and morphogenesis of craniofacial muscles. Dev Dyn 235, 1194, 2006.

38. Nathan, E., Monovich, A., Tirosh-Finkel, L., Harrelson, Z., Rousso, T., Rinon, A., Harel, I., Evans, S.M., and Tzahor, E. The contribution of Islet1-expressing splanchnic mesoderm cells to distinct branchiomeric muscles reveals significant 
heterogeneity in head muscle development. Development 135, 647, 2008.

39. Ono, Y., Boldrin, L., Knopp, P., Morgan, J.E., and Zammit, P.S. Muscle satellite cells are a functionally heterogeneous population in both somite-derived and branchiomeric muscles. Dev Biol 337, 29, 2010.

40. Pavlath, G.K., Thaloor, D., Rando, T.A., Cheong, M., English, A.W., and Zheng, B. Heterogeneity among muscle precursor cells in adult skeletal muscles with differing regenerative capacities. Dev Dyn 212, 495, 1998.

41. Schmalbruch, H., and Hellhammer, U. The number of nuclei in adult rat muscles with special reference to satellite cells. Anat Rec 189, 169, 1977.

42. Gibson, M.C., and Schultz, E. The distribution of satellite cells and their relationship to specific fiber types in soleus and extensor digitorum longus muscles. Anat $\operatorname{Rec} 202,329$, 1982.

43. Schultz, E., Darr, K.C., and Macius, A. Acute effects of hindlimb unweighting on satellite cells of growing skeletal muscle. J Appl Physiol 76, 266, 1994.

44. Mozdziak, P.E., Truong, Q., Macius, A., and Schultz, E. Hindlimb suspension reduces muscle regeneration. Eur J Appl Physiol Occup Physiol 78, 136, 1998.

45. Mozdziak, P.E., Pulvermacher, P.M., and Schultz, E. Muscle regeneration during hindlimb unloading results in a reduction in muscle size after reloading. J Appl Physiol 91, 183, 2001.

46. Kohno, S., Yamashita, Y., Abe, T., Hirasaka, K., Oarada, M., Ohno, A., Teshima-Kondo, S., Higashibata, A., Choi, I., Mills, E.M., Okumura, Y., Terao, J., and Nikawa, T. Unloading stress disturbs muscle regeneration through perturbed recruitment and function of macrophages. J Appl Physiol 112, 1777, 2012.

47. Butler-Browne, G.S., and Whalen, R.G. Myosin isozyme transitions occurring during the postnatal development of the rat soleus muscle. Dev Biol 102, 324, 1984.

48. Ferguson, M.W. Palatal shelf elevation in the Wistar rat fetus. J Anat 125, 555, 1978.

49. Ferguson, M.W. Developmental mechanisms in normal and abnormal palate formation with particular reference to the aetiology, pathogenesis and prevention of cleft palate. Br J Orthod 8, 115, 1981.

50. Gritli-Linde, A. The etiopathogenesis of cleft lip and cleft palate: usefulness and caveats of mouse models. Curr Top Dev Biol 84, 37, 2008.

51. Weinzweig, J., Panter, K.E., Pantaloni, M., Spangenberger, A., Harper, J.S., Lui, F., Gardner, D., Wierenga, T.L., and Edstrom, L.E. The fetal cleft palate: I. Characterization of a congenital model. Plast Reconstr Surg 103, 419, 1999.

52. Schupbach, P.M. Experimental induction of an incomplete hard-palate cleft in the rat. Oral Surg Oral Med Oral Pathol 55, 2, 1983.

53. Schupbach, P.M., Dorig-Schwarzenbach, A.G., and Schroeder, H.E. Rare total and partial palatal clefts experimentally induced in the rat. Cleft Palate J 21, 204, 1984.

54. Weinzweig, J., Panter, K.E., Patel, J., Smith, D.M., Spangenberger, A., and Freeman, M.B. The fetal cleft palate: v. elucidation of the mechanism of palatal clefting in the congenital caprine model. Plast Reconstr Surg 121, 1328, 2008.

55. Weinzweig, J., Panter, K.E., Seki, J., Pantaloni, M., Spangenberger, A., and Harper, J.S. The fetal cleft palate: IV. Midfacial growth and bony palatal development following in utero and neonatal repair of the congenital caprine model. Plast Reconstr Surg 118, 81, 2006.
56. Weinzweig, J., Panter, K.E., Spangenberger, A., Harper, J.S., McRae, R., and Edstrom, L.E. The fetal cleft palate: III. Ultrastructural and functional analysis of palatal development following in utero repair of the congenital model. Plast Reconstr Surg 109, 2355, 2002.

57. Cui, X.M., Shiomi, N., Chen, J., Saito, T., Yamamoto, T., Ito, Y., Bringas, P., Chai, Y., and Shuler, C.F. Overexpression of Smad2 in Tgf-beta3-null mutant mice rescues cleft palate. Dev Biol 278, 193, 2005.

58. Kaartinen, V., Voncken, J.W., Shuler, C., Warburton, D., Bu, D., Heisterkamp, N., and Groffen, J. Abnormal lung development and cleft palate in mice lacking TGF-beta 3 indicates defects of epithelial-mesenchymal interaction. Nat Genet 11, 415, 1995.

59. Proetzel, G., Pawlowski, S.A., Wiles, M.V., Yin, M., Boivin, G.P., Howles, P.N., Ding, J., Ferguson, M.W., and Doetschman, T. Transforming growth factor-beta 3 is required for secondary palate fusion. Nat Genet 11, 409, 1995.

60. Koo, S.H., Cunningham, M.C., Arabshahi, B., Gruss, J.S., and Grant, J.H., 3rd. The transforming growth factor-beta 3 knock-out mouse: an animal model for cleft palate. Plast Reconstr Surg 108, 938, 2001.

61. Yasuda, K., Okuda, D., Tanaka, M., Mori, R., Hasumi-Nakayama, Y., Tanaka, M., Yamaoka, M., and Furusawa, K. Central distribution of neuronal cell bodies innervating the levator veli palatini muscle and associated pattern of myosin heavy chain isoform expression in rat. Brain Res 968, 80, 2003.

62. Furusawa, K., Yamaoka, M., Kogo, M., and Matsuya, T. The innervation of the levator veli palatini muscle by the glossopharyngeal nerve. Brain Res Bull 26, 599, 1991.

63. Trotman, C.A., Hou, D., Burdi, A.R., Cohen, S.R., and Carlson, D.S. Histomorphologic analysis of the soft palate musculature in prenatal cleft and noncleft A/Jax mice. Cleft Palate Craniofac J 32, 455, 1995.

64. Schultz, E. Fine structure of satellite cells in growing skeletal muscle. Am J Anat 147, 49, 1976.

65. Allbrook, D.B., Han, M.F., and Hellmuth, A.E. Population of muscle satellite cells in relation to age and mitotic activity. Pathology 3, 223, 1971.

66. Cardasis, C.A., and Cooper, G.W. An analysis of nuclear numbers in individual muscle fibers during differentiation and growth: a satellite cell-muscle fiber growth unit. J Exp Zool 191, 347, 1975.

67. Schmalbruch, H., and Hellhammer, U. The number of satellite cells in normal human muscle. Anat Rec 185, 279, 1976.

68. Creuzet, S., Lescaudron, L., Li, Z., and Fontaine-Perus, J. MyoD, myogenin, and desmin-nls-lac $Z$ transgene emphasize the distinct patterns of satellite cell activation in growth and regeneration. Exp Cell Res 243, 241, 1998.

69. Lee-Pullen, T.F., Bennett, A.L., Beilharz, M.W., Grounds, M.D., and Sammels, L.M. Superior survival and proliferation after transplantation of myoblasts obtained from adult mice compared with neonatal mice. Transplantation 78, $1172,2004$.

70. Collins, C.A., Olsen, I., Zammit, P.S., Heslop, L., Petrie, A., Partridge, T.A., and Morgan, J.E. Stem cell function, selfrenewal, and behavioral heterogeneity of cells from the adult muscle satellite cell niche. Cell 122, 289, 2005.

71. Law, P.K., Goodwin, T.G., Fang, Q., Deering, M.B., Duggirala, V., Larkin, C., Florendo, J.A., Kirby, D.S., Li, H.J., Chen, M., et al. Cell transplantation as an experimental treatment for Duchenne muscular dystrophy. Cell Transplant 2, 485, 1993. 
72. Cousins, J.C., Woodward, K.J., Gross, J.G., Partridge, T.A., and Morgan, J.E. Regeneration of skeletal muscle from transplanted immortalised myoblasts is oligoclonal. J Cell Sci 117, 3259, 2004.

73. Menasche, P. Cardiac cell therapy trials: chronic myocardial infarction and congestive heart failure. J Cardiovasc Transl Res 1, 201, 2008.

74. Menasche, P. Cardiac cell therapy: lessons from clinical trials. J Mol Cell Cardiol 50, 258, 2010.

75. Montarras, D., Morgan, J., Collins, C., Relaix, F., Zaffran, S., Cumano, A., Partridge, T., and Buckingham, M. Direct isolation of satellite cells for skeletal muscle regeneration. Science 309, 2064, 2005.

76. Fan, Y., Maley, M., Beilharz, M., and Grounds, M. Rapid death of injected myoblasts in myoblast transfer therapy. Muscle Nerve 19, 853, 1996.

77. Barberi, T., Willis, L.M., Socci, N.D., and Studer, L. Derivation of multipotent mesenchymal precursors from human embryonic stem cells. PLoS Med 2, e161, 2005.

78. Ferrari, G., Cusella-De Angelis, G., Coletta, M., Paolucci, E., Stornaiuolo, A., Cossu, G., and Mavilio, F. Muscle regeneration by bone marrow-derived myogenic progenitors. Science 279, 1528, 1998.

79. Muguruma, Y., Reyes, M., Nakamura, Y., Sato, T., Matsuzawa, H., Miyatake, H., Akatsuka, A., Itoh, J., Yahata, T., Ando, K., Kato, S., and Hotta, T. In vivo and in vitro differentiation of myocytes from human bone marrow-derived multipotent progenitor cells. Exp Hematol 31, 1323, 2003.

80. Wang, Y.X., and Rudnicki, M.A. Satellite cells, the engines of muscle repair. Nat Rev Mol Cell Biol 13, 127, 2012.

81. Otto, A., Collins-Hooper, H., and Patel, K. The origin, molecular regulation and therapeutic potential of myogenic stem cell populations. J Anat 215, 477, 2009.

82. Robinton, D.A., and Daley, G.Q. The promise of induced pluripotent stem cells in research and therapy. Nature 481, 295, 2012.

83. Evans, M. Discovering pluripotency: 30 years of mouse embryonic stem cells. Nat Rev Mol Cell Biol 12, 680, 2011.

84. Darabi, R., Gehlbach, K., Bachoo, R.M., Kamath, S., Osawa, M., Kamm, K.E., Kyba, M., and Perlingeiro, R.C. Functional skeletal muscle regeneration from differentiating embryonic stem cells. Nat Med 14, 134, 2008.

85. Cossu, G., and Bianco, P. Mesoangioblasts-vascular progenitors for extravascular mesodermal tissues. Curr Opin Genet Dev 13, 537, 2003.

86. Dellavalle, A., Sampaolesi, M., Tonlorenzi, R., Tagliafico, E., Sacchetti, B., Perani, L., Innocenzi, A., Galvez, B.G., Messina, G., Morosetti, R., Li, S., Belicchi, M., Peretti, G., Chamberlain, J.S., Wright, W.E., Torrente, Y., Ferrari, S., Bianco, P., and Cossu, G. Pericytes of human skeletal muscle are myogenic precursors distinct from satellite cells. Nat Cell Biol 9, 255, 2007.

87. Sampaolesi, M., Torrente, Y., Innocenzi, A., Tonlorenzi, R., D'Antona, G., Pellegrino, M.A., Barresi, R., Bresolin, N., De Angelis, M.G., Campbell, K.P., Bottinelli, R., and Cossu, G. Cell therapy of alpha-sarcoglycan null dystrophic mice through intra-arterial delivery of mesoangioblasts. Science 301, 487, 2003.

88. Cossu, G., and Biressi, S. Satellite cells, myoblasts and other occasional myogenic progenitors: possible origin, phenotypic features and role in muscle regeneration. Semin Cell Dev Biol 16, 623, 2005.

89. Qu-Petersen, Z., Deasy, B., Jankowski, R., Ikezawa, M., Cummins, J., Pruchnic, R., Mytinger, J., Cao, B., Gates, C.,
Wernig, A., and Huard, J. Identification of a novel population of muscle stem cells in mice: potential for muscle regeneration. J Cell Biol 157, 851, 2002.

90. Zammit, P.S. All muscle satellite cells are equal, but are some more equal than others? J Cell Sci 121, 2975, 2008.

91. Tedesco, F.S., Dellavalle, A., Diaz-Manera, J., Messina, G., and Cossu, G. Repairing skeletal muscle: regenerative potential of skeletal muscle stem cells. J Clin Invest 120, 11, 2010.

92. Sato, K., Li, Y., Foster, W., Fukushima, K., Badlani, N., Adachi, N., Usas, A., Fu, F.H., and Huard, J. Improvement of muscle healing through enhancement of muscle regeneration and prevention of fibrosis. Muscle Nerve 28, 365, 2003.

93. Falco, E.E., Wang, M.O., Thompson, J.A., Chetta, J.M., Yoon, D.M., Li, E.Z., Kulkami, M.M., Shah, S., Pandit, A., Roth, J.S., and Fisher, J.P. Porous EH and EH-PEG scaffolds as gene delivery vehicles to skeletal muscle. Pharm Res 28, 1306, 2011.

94. Musaro, A., Giacinti, C., Borsellino, G., Dobrowolny, G., Pelosi, L., Cairns, L., Ottolenghi, S., Cossu, G., Bernardi, G., Battistini, L., Molinaro, M., and Rosenthal, N. Stem cellmediated muscle regeneration is enhanced by local isoform of insulin-like growth factor 1. Proc Natl Acad Sci U S A 101, 1206, 2004.

95. Barton-Davis, E.R., Shoturma, D.I., Musaro, A., Rosenthal, N., and Sweeney, H.L. Viral mediated expression of insulin-like growth factor I blocks the aging-related loss of skeletal muscle function. Proc Natl Acad Sci U S A 95, 15603, 1998.

96. Allen, R.E., and Boxhorn, L.K. Regulation of skeletal muscle satellite cell proliferation and differentiation by transforming growth factor-beta, insulin-like growth factor I, and fibroblast growth factor. J Cell Physiol 138, 311, 1989.

97. Guthridge, M., Wilson, M., Cowling, J., Bertolini, J., and Hearn, M.T. The role of basic fibroblast growth factor in skeletal muscle regeneration. Growth Factors 6, 53, 1992.

98. Lefaucheur, J.P., and Sebille, A. Basic fibroblast growth factor promotes in vivo muscle regeneration in murine muscular dystrophy. Neurosci Lett 202, 121, 1995.

99. Yoshida, S., Fujisawa-Sehara, A., Taki, T., Arai, K., and Nabeshima, Y. Lysophosphatidic acid and bFGF control different modes in proliferating myoblasts. J Cell Biol 132, 181, 1996.

100. Yun, Y.R., Lee, S., Jeon, E., Kang, W., Kim, K.H., Kim, H.W., and Jang, J.H. Fibroblast growth factor 2-functionalized collagen matrices for skeletal muscle tissue engineering. Biotechnol Lett 34, 771, 2012.

101. Yablonka-Reuveni, Z., Seger, R., and Rivera, A.J. Fibroblast growth factor promotes recruitment of skeletal muscle satellite cells in young and old rats. J Histochem Cytochem 47, 23, 1999.

102. Lefaucheur, J.P., Gjata, B., Lafont, H., and Sebille, A. Angiogenic and inflammatory responses following skeletal muscle injury are altered by immune neutralization of endogenous basic fibroblast growth factor, insulin-like growth factor-1 and transforming growth factor-beta 1 . J Neuroimmunol 70, 37, 1996.

103. Li, J., Wei, Y., Liu, K., Yuan, C., Tang, Y., Quan, Q., Chen, P., Wang, W., Hu, H., and Yang, L. Synergistic effects of FGF-2 and PDGF-BB on angiogenesis and muscle regeneration in rabbit hindlimb ischemia model. Microvasc Res 80, 10, 2010.

104. Andreopoulos, F.M., and Persaud, I. Delivery of basic fibroblast growth factor (bFGF) from photoresponsive hydrogel scaffolds. Biomaterials 27, 2468, 2006. 
105. Whitaker, M.J., Quirk, R.A., Howdle, S.M., and Shakesheff, K.M. Growth factor release from tissue engineering scaffolds. J Pharm Pharmacol 53, 1427, 2001.

106. Rui, J., Dadsetan, M., Runge, M.B., Spinner, R.J., Yaszemski, M.J., Windebank, A.J., and Wang, H. Controlled release of vascular endothelial growth factor using polylactic-co-glycolic acid microspheres: In vitro characterization and application in polycaprolactone fumarate nerve conduits. Acta Biomater 8, 511, 2011.

107. Layman, H., Li, X., Nagar, E., Vial, X., Pham, S.M., and Andreopoulos, F.M. Enhanced angiogenic efficacy through controlled and sustained delivery of FGF-2 and G-CSF from fibrin hydrogels containing ionic-albumin microspheres. J Biomater Sci Polym Ed 23, 185, 2012.

108. Lee, J., Bhang, S.H., Park, H., Kim, B.S., and Lee, K.Y. Active blood vessel formation in the ischemic hindlimb mouse model using a microsphere/hydrogel combination system. Pharm Res 27, 767, 2010.

109. Briganti, E., Spiller, D., Mirtelli, C., Kull, S., Counoupas, C., Losi, P., Senesi, S., Di Stefano, R., and Soldani, G. A composite fibrin-based scaffold for controlled delivery of bioactive pro-angiogenetic growth factors. J Control Release 142, 14, 2010.

110. de la Puente, P., Ludena, D., Fernandez, A., Aranda, J.L., Varela, G., and Iglesias, J. Autologous fibrin scaffolds cultured dermal fibroblasts and enriched with encapsulated bFGF for tissue engineering. J Biomed Mater Res A 99, 648, 2011.

111. Layman, H., Sacasa, M., Murphy, A.E., Murphy, A.M., Pham, S.M., and Andreopoulos, F.M. Co-delivery of FGF-2 and G-CSF from gelatin-based hydrogels as angiogenic therapy in a murine critical limb ischemic model. Acta Biomater 5, 230, 2009.

112. Losi, P., Briganti, E., Magera, A., Spiller, D., Ristori, C., Battolla, B., Balderi, M., Kull, S., Balbarini, A., Di Stefano, R., and Soldani, G. Tissue response to poly(ether)urethanepolydimethylsiloxane-fibrin composite scaffolds for controlled delivery of pro-angiogenic growth factors. Biomaterials 31, 5336, 2010.

113. Jejurikar, S.S., and Kuzon, W.M., Jr. Satellite cell depletion in degenerative skeletal muscle. Apoptosis 8, 573, 2003.

114. Okano, T., Satoh, S., Oka, T., and Matsuda, T. Tissue engineering of skeletal muscle. Highly dense, highly oriented hybrid muscular tissues biomimicking native tissues. Asaio J 43, M749, 1997.

115. Zhao, Y., Zeng, H., Nam, J., and Agarwal, S. Fabrication of skeletal muscle constructs by topographic activation of cell alignment. Biotechnol Bioeng 102, 624, 2009.

116. Desai, T.A. Micro- and nanoscale structures for tissue engineering constructs. Med Eng Phys 22, 595, 2000.

117. McKeon-Fischer, K.D., and Freeman, J.W. Characterization of electrospun poly(L-lactide) and gold nanoparticle composite scaffolds for skeletal muscle tissue engineering. J Tissue Eng Regen Med 5, 560, 2011.

118. Altomare, L., Riehle, M., Gadegaard, N., Tanzi, M.C., and Fare, S. Microcontact printing of fibronectin on a biodegradable polymeric surface for skeletal muscle cell orientation. Int J Artif Organs 33, 535, 2010.

119. Wang, P.Y., Yu, H.T., and Tsai, W.B. Modulation of alignment and differentiation of skeletal myoblasts by submicron ridges/grooves surface structure. Biotechnol Bioeng 106, 285, 2010.

120. Caliari, S.R., and Harley, B.A. The effect of anisotropic collagen-GAG scaffolds and growth factor supplementa- tion on tendon cell recruitment, alignment, and metabolic activity. Biomaterials 32, 5330, 2011.

121. Xu, C.Y., Inai, R., Kotaki, M., and Ramakrishna, S. Aligned biodegradable nanofibrous structure: a potential scaffold for blood vessel engineering. Biomaterials 25, 877, 2004.

122. Ker, E.D., Nain, A.S., Weiss, L.E., Wang, J., Suhan, J., Amon, C.H., and Campbell, P.G. Bioprinting of growth factors onto aligned sub-micron fibrous scaffolds for simultaneous control of cell differentiation and alignment. Biomaterials 32, 8097, 2011.

123. Ker, E.D., Chu, B., Phillippi, J.A., Gharaibeh, B., Huard, J., Weiss, L.E., and Campbell, P.G. Engineering spatial control of multiple differentiation fates within a stem cell population. Biomaterials 32, 3413, 2011.

124. Grefte, S., Kuijpers-Jagtman, A.M., Torensma, R., and Von den Hoff, J.W. Skeletal muscle fibrosis: the effect of stromalderived factor-1 $\alpha$-loaded collagen scaffolds. Regen Med 5, 737, 2010.

125. Lu, Y., Shi, B., Zheng, Q., Xiao, W., and Li, S. Analysis of velopharyngeal morphology in adults with velopharyngeal incompetence after surgery of a cleft palate. Ann Plast Surg 57, 50, 2006.

126. Oyama, T., Nishimoto, S., Ishii, N., and Hosokawa, K. Soft palate mucosal adhesion as a preparation for Furlow's double-opposing Z-palatoplasty. Plast Reconstr Surg 118, 469, 2006.

127. Nishio, J., Yamanishi, T., Kohara, H., Hirano, Y., Sako, M., Adachi, T., Mukai, T., and Miya, S. Early two-stage palatoplasty using modified Furlow's veloplasty. Cleft Palate Craniofac J 47, 73, 2010.

128. Lohmander-Agerskov, A., Soderpalm, E., Friede, H., and Lilja, J. Cleft lip and palate patients prior to delayed closure of the hard palate: evaluation of maxillary morphology and the effect of early stimulation on pre-school speech. Scand J Plast Reconstr Surg Hand Surg 24, 141, 1990.

129. Eberlinc, A., and Kozelj, V. Incidence of residual oronasal fistulas: a 20-year experience. Cleft Palate Craniofac J 2011 [Epub ahead of print]; DOI: http://dx.doi.org/10.1597/10-146.

130. Andersson, E.M., Sandvik, L., Semb, G., and Abyholm, F. Palatal fistulas after primary repair of clefts of the secondary palate. Scand J Plast Reconstr Surg Hand Surg 42, 296, 2008.

131. Losee, J.E., and Smith, D.M. Acellular dermal matrix in palatoplasty. Aesthet Surg J 31, 108S, 2011.

132. Li, Y., Foster, W., Deasy, B.M., Chan, Y., Prisk, V., Tang, Y., Cummins, J., and Huard, J. Transforming growth factorbeta1 induces the differentiation of myogenic cells into fibrotic cells in injured skeletal muscle: a key event in muscle fibrogenesis. Am J Pathol 164, 1007, 2004.

133. Mendias, C.L., Gumucio, J.P., Davis, M.E., Bromley, C.W., Davis, C.S., and Brooks, S.V. Transforming growth factorbeta induces skeletal muscle atrophy and fibrosis through the induction of atrogin-1 and scleraxis. Muscle Nerve 45, 55, 2012.

134. Border, W.A., and Noble, N.A. Transforming growth factor beta in tissue fibrosis. N Engl J Med 331, 1286, 1994.

135. Thomas, M., Langley, B., Berry, C., Sharma, M., Kirk, S., Bass, J., and Kambadur, R. Myostatin, a negative regulator of muscle growth, functions by inhibiting myoblast proliferation. J Biol Chem 275, 40235, 2000.

136. Rios, R., Carneiro, I., Arce, V.M., and Devesa, J. Myostatin is an inhibitor of myogenic differentiation. Am J Physiol Cell Physiol 282, C993, 2002. 
137. McPherron, A.C., Lawler, A.M., and Lee, S.J. Regulation of skeletal muscle mass in mice by a new TGF-beta superfamily member. Nature 387, 83, 1997.

138. Abe, S., Hirose, D., Kado, S., Iwanuma, O., Saka, H., Yanagisawa, N., and Ide, Y. Increased expression of decorin during the regeneration stage of $\mathrm{mdx}$ mouse. Anat Sci Int 84, 305, 2009.

139. Zhu, J., Li, Y., Shen, W., Qiao, C., Ambrosio, F., Lavasani, M., Nozaki, M., Branca, M.F., and Huard, J. Relationships between transforming growth factor-beta1, myostatin, and decorin: implications for skeletal muscle fibrosis. J Biol Chem 282, 25852, 2007.

140. Takeuchi, Y., Kodama, Y., and Matsumoto, T. Bone matrix decorin binds transforming growth factor-beta and enhances its bioactivity. J Biol Chem 269, 32634, 1994.

141. Schonherr, E., Broszat, M., Brandan, E., Bruckner, P., and Kresse, H. Decorin core protein fragment Leu155-Val260 interacts with TGF-beta but does not compete for decorin binding to type I collagen. Arch Biochem Biophys 355, 241, 1998.

142. Whittemore, L.A., Song, K., Li, X., Aghajanian, J., Davies, M., Girgenrath, S., Hill, J.J., Jalenak, M., Kelley, P., Knight, A., Maylor, R., O'Hara, D., Pearson, A., Quazi, A., Ryerson, S., Tan, X.Y., Tomkinson, K.N., Veldman, G.M., Widom, A., Wright, J.F., Wudyka, S., Zhao, L., and Wolfman, N.M. Inhibition of myostatin in adult mice increases skeletal muscle mass and strength. Biochem Biophys Res Commun 300, 965, 2003.

143. Kishioka, Y., Thomas, M., Wakamatsu, J., Hattori, A., Sharma, M., Kambadur, R., and Nishimura, T. Decorin enhances the proliferation and differentiation of myogenic cells through suppressing myostatin activity. J Cell Physiol 215, 856, 2008.

144. Fukushima, K., Badlani, N., Usas, A., Riano, F., Fu, F., and Huard, J. The use of an antifibrosis agent to improve muscle recovery after laceration. Am J Sports Med 29, 394, 2001.

145. Li, Y., Li, J., Zhu, J., Sun, B., Branca, M., Tang, Y., Foster, W., Xiao, X., and Huard, J. Decorin gene transfer promotes muscle cell differentiation and muscle regeneration. Mol Ther 15, 1616, 2007.

146. Kobayashi, E., Sasamura, H., Mifune, M., Shimizu-Hirota, R., Kuroda, M., Hayashi, M., and Saruta, T. Hepatocyte growth factor regulates proteoglycan synthesis in interstitial fibroblasts. Kidney Int 64, 1179, 2003.

147. Filippin, L.I., Moreira, A.J., Marroni, N.P., and Xavier, R.M. Nitric oxide and repair of skeletal muscle injury. Nitric Oxide 21, 157, 2009.

Address correspondence to: Johannes W. Von den Hoff, Ph.D. Department of Orthodontics and Craniofacial Biology Nijmegen Centre for Molecular Life Sciences Radboud University Nijmegen Medical Centre P.O. Box 9101 6500 HB Nijmegen The Netherlands

E-mail: h.vondenhoff@dent.umcn.nl

Received: January 27, 2012 Accepted: June 12, 2012

Online Publication Date: July 18, 2012 